\title{
Assessment Practices among English Teachers in Malaysian Secondary Schools
}

\author{
Arsaythamby Veloo ${ }^{1}$, Rosidah Ramli ${ }^{2}$, Rozalina Khalid ${ }^{1}$ \\ Universiti Utara Malaysia ${ }^{1}$, Marang Secondary School ${ }^{2}$ \\ Malaysia
}

\begin{abstract}
Previous studies in other countries showed that the implementation of School Based Assessment has given positive impact on teachers' teaching and learning processes and also students' growth. Therefore, this study aims to obtain information on English Language Teachers' assessment practices in Malaysian Seconday Schools. An adaptation of twopart questionnaire from the Assessment Practices Inventory (API) was administered to 49 English teachers in Terengganu, Malaysia followed by a semistructured interview conducted on 15 teachers to get deeper understanding of their assessment practices. The finding of this study shows that teachers' SBA practices are at an average level. The significant difference between the assessment practices of the teachers who had attended any courses on SBA and the teachers who had not showed that SBA courses do have impact on the effectiveness of SBA implementation. It is hoped that the findings of this survey will contribute to the teachers' knowledge in creating a culture of practicing a meaningful and effective classroom assessment. If a quality assessment is able to show an accurate data of students' progress and potential development while simultaneously improve teachers' teaching and learning processes, the objective of SBA implementation will be considered as successfully achieved.
\end{abstract}

\section{Introduction}

It could not be denied that assessment is an important component in education. Besides providing information about students' learning development, it also helps teachers to assess their teaching methods. Assessment defined as a process where humans collect data with the purpose of making decisions [1]. Meanwhile, claimed that assessment is a process of considering the individual's learning achievement level or the effectiveness of a certain product based on the data collected [2]. Education scenario in Malaysia which emphasises on the numbers of $\mathrm{A}$ obtained by the students has influenced the teaching and learning process in the classroom [3]. Teachers are inclined to only give drilling exercises based on the questions that usually would be asked in the examination, which indirectly has made memorization or rote learning a culture among students [4].

Thus, realizing that we aim to produce balanced human capital with skills needed in the 21 st century, MOE has introduced the National Education Assessment System (SPPN) through the national education assessment transformation in December, 2010 [5]. SPPN was introduced to replace the present assessment system was said to have imposed much stress among students, schools and also parents because of the grade driven culture. SPPN is a system that is comprehensive, flexible, balanced and referred to the standard which is able to collate information about the students' development and also information on how to use that information to improve teaching. SPPN comprises of two main components that are centralized examination such as (Primary School Evaluation Test (UPSR), Malaysian Certificate of Education (SPM) and (Malaysian Higher Education Certificate (STPM) and SBA.

SBA was gradually introduced in primary schools in 2011 followed by the lower secondary schools in 2012. Through the implementation of SBA, teachers are given the autonomy from determining the output to be assessed, planning, constructing the assessment instrument, recording, analysing and reporting the assessment output which ends with following up [6]. Based on this fact, it is obvious that the teachers' role is very important. However, to ensure that assessment is valid, reliable and accurate, teachers have to have adequate knowledge and skills. In addition, teachers have to be smart in using the output to determine students' strengths and weaknesses while at the same time identify the effectiveness of their own teaching so that improvements can be made for the betterment of the students. SBA practices among teachers were at an unsatisfactory level [7]. Moreover, the teachers lack knowledge and skill in implementing SBA and consequently affecting the teachers' level of confidence in assessing their [8]. Teachers were also 
found to have problems in constructing the assessment instrument [9], [10]. Teachers also have the tendency to give high marks to their favourite students and teachers usually have transparency issues in terms of allotting bands to the students because teachers are soft-hearted towards their students [11]. The above issues have raised serious questions regarding teachers' real assessment practice in implementing SBA. Therefore, after four years of SBA implementation, the researchers would like to further expand previous studies by identifying teachers' assessment practice so that appropriate actions can be taken to better teachers' understanding and practice of assessment in schools.

In reality, assessment and examination have somewhat put pressure on teachers and school administrators in terms of time and effort to prepare students for successful performance. For example, in the Malaysian scenario, leaks in the examination questions of several subjects during UPSR 2014 have shown that students, parents as well as teachers were pushed into producing good results in the public examination and increasing the School Average Grade (GPS) but at the same time putting aside integrity, trust and authority as long as they gain the 'A' they desired. This incident has somewhat opened the eyes of the society that all this while we are practicing the wrong way of measuring success and this is where the weaknesses of the assessment system lie. This issue was addressed the increasing pressure due to assessment practice has affected students and schools [12]. Among them is the focused-test whereby memorization or rote learning is emphasized; which is rigid and has caused lack in practicing the Higher Order Thinking Skills (HOTS) among the students. Teachers too were found not practicing the teaching and learning theories that they have learnt or being exposed to; and instead they are drilling the students with past years examination topics and answering formats which make their lessons uninsteresting [12]. In addition, teaching is now considered as a serious preparation towards making students perform in high stake examinations or end of the year summative examination [13].

The implementation of SBA in Malaysia which was introduced in 2011 in primary schools and 2012 in secondary schools consist of four main components namely School Assessment, Centre Assessment, Psychometric Assessment and Physical Activity, Sports and Cocurriculum Assessment [5]. Through School Assessment, teachers are given the autonomy to implement formative assessment (done during teaching and learning sessions) and summative assessment (done after teaching and learning sessions) based on own schools' level. This type of assessment is planned, designed, administered, examined, recorded and reported totally by the school teachers.

\section{Teachers' Assessment Practice}

In the education world, assessment is an important component and is implemented to identify students' present status [7]. However, big scale assessment such as public examinations which has the purpose of placing ranks on students and schools is not a good tool to help teachers in improvising or gearing their teaching towards the needs of their students [14]. This is because the public examinations are usually conducted at the end of the year where teaching sessions have ended. In fact, the result obtained are not detailed which could help teachers in improving their teaching [15]. In addition, those who support high stake assessment also realized that standard test could not fully fulfill the important aims of teaching.

An effective and quality assessment could increase $15-20 \%$ of students' achievement to the extent that 'a good teaching is impossible without a good assessment' [16]. Among the best assessment in helping students' learning are quizzes, tests, writing tasks and other types of assessments which are administered by teachers in the classroom [14].

Teachers' SBA practice is important so as to achieve the expected aims. Nevertheless, many researchers have voiced out their concern about the dissimilarity between the actual SBA practice and the present SBA practice in schools [17]. Assessment practice among 246 teachers in Oman found that the teachers were inclined to choose the traditional assessment method compared to the alternative assessment [18]. For instance, when conducting assessment, teachers did not prepare the Test Specification Table (TST) to help them plan the tested contents nor the marking scheme which made the assessment loose its content validity [9]. In fact, in the standard test, teachers were reported to practice teaching to the test, giving extra time to students, and to the extent of amending the students' answers and teachers agree students' grade be increased if they have succeeded to achieve the learning objectives although the students might not be able to complete their tasks [19]. There was also a case whereby teachers label their students and were biased when conducting the assessment [5]. Besides that, the researchers also claimed that teachers who have ethics should be aware of the factors that will influence the transparency in allotting grades to the students.

Assessment skill and practice are related but with different constructs. Assessment practice is related to teachers' assessment activities whereas assessment skill mirrors teachers' perception of their skill level in 
conducting assessment activities. This has become the reason teachers consider themselves to be assessment literate but at the same time they do not have the readiness to conduct classroom assessment. They also stated that the scope of classroom assessment is very wide [20]. It is clear that assessment is one of the most important and difficult components in a teacher's work. It can be seen as a way to help teachers in facilitating students' learning.

\section{Objective of Study}

This study aims to identify the assessment practice of the English language teachers in implementing SBA based on the Skill of constructing assessment instruments, Use of types of assessment, Scoring and grading, Use of assessment information and Assessment etiquette.

\section{Methodology}

In gathering meaningful information from the English teachers involved in the SBA implementation in the Marang district, the targeted population is teachers who teach the English language in Forms 1, 2 and 3 in all the 13 schools. Table 1 shows the number of English language teachers in 2015 based on the data collected from Marang District Education Office. There are 49 teachers in Forms 1, 2 and 3 and this number is taken as the population for this study.

Table 1. Type of Secondary School and Tecahers

\begin{tabular}{|l|c|c|}
\hline Type & $\begin{array}{c}\text { No. of } \\
\text { schools }\end{array}$ & $\begin{array}{c}\text { No. of } \\
\text { teachers }\end{array}$ \\
\hline Grade A Schools & 8 & 30 \\
Grade B Schools & 5 & 19 \\
\hline & 13 & 49 \\
\hline
\end{tabular}

\subsection{Questionnaire}

(PPD Marang, 2015)

The study instrument is adopted and adapted from Assessment Practices Inventory (API) which consists of 54 items related to SBA practice and was prepared in the Malay language [19] (see Table 2). This instrument uses the 5 point Likert scale; 1 (Never), 2 (Seldom), 3 (Sometimes), 4 (Often) and 5 (Very Often).

\subsection{Structured Interview}

To conduct the interview with 15 selected teachers, a structured interview guideline was prepared to get more information. The interview protocols focused on the following: i. SBA implementation process

ii.Issues and problems in assesment

iii.The interview transcripts were analysed. Researchers coded each unit sentence to identify the related themes to strengthen the result findings.

Table 2: Distribution of variables in SBA Practice

\begin{tabular}{|c|c|c|c|}
\hline No & SBA Practice & $\begin{array}{l}\text { Items } \\
\text { Nos }\end{array}$ & $\begin{array}{l}\text { Total } \\
\text { Items }\end{array}$ \\
\hline 1 & $\begin{array}{l}\text { Skill of constructing } \\
\text { assessment } \\
\text { instruments }\end{array}$ & $1-18$ & 18 \\
\hline 2 & $\begin{array}{l}\text { Use of types of } \\
\text { assessment }\end{array}$ & 19- 23 & 5 \\
\hline 3 & $\begin{array}{l}\text { Scoring and grading } \\
\text { practice }\end{array}$ & $24-37$ & 14 \\
\hline 4 & $\begin{array}{l}\text { Use of assessment } \\
\text { information }\end{array}$ & $38-45$ & 8 \\
\hline 5 & Assessment ethics & 46- 50 & 5 \\
\hline \multicolumn{3}{|c|}{ Total } & 50 \\
\hline
\end{tabular}

\subsection{Validity and Reliability}

The instrument for this study was adapted from Assessment Practices Inventory (API) which was produced by [19]. For translation purposes, the researchers have used back translation where all the items were translated into the Malay language before they were retranslated to English with the help of the English language Head Panitia, Senior Head for Languages and SIC to ensure its validity.

Consequently, the questionnaire items were given to 5 experienced Malay language teachers for the proofing process. This instrument was piloted on 30 Forms 1, 23 teachers in 5 selected secondary schools to measure its reliability. The reliability index obtained was .97 and a translated instrument is considered as a new instrument and an alpha value greater than .70 is sufficient [20].

To prove that all six variable constructs are homogenous, internal consistency reliability for each variable was also calculated using Alpha Cronbach (Table 3). All the items showed a high Corrected Item-total Correlation. The Alpha Cronbach values for the skill of constructing assessment instruments, use of types of assessment, scoring and grading practice, use of assessment information and assessment ethics are masing $.96, .88, .96, .92, .84$ dan .91 consecutively. 
Table 3. Reliability index for questionnaire items

\begin{tabular}{|c|c|c|c|c|}
\hline No & SBA practice & Items & $\begin{array}{l}\text { Corrected } \\
\text { Item-total } \\
\text { Correlation }\end{array}$ & $\alpha$ \\
\hline 1 & $\begin{array}{l}\text { Skill of } \\
\text { constructing } \\
\text { assessment } \\
\text { instruments }\end{array}$ & 18 & $\begin{array}{lll}.67 & .46 & .74 \\
.84 & .82 & .75 \\
.84 & .75 & .75 \\
.92 & .87 & .87 \\
.73 & .74 & .75 \\
.75 & .78 & .75\end{array}$ & .96 \\
\hline 2 & $\begin{array}{l}\text { Use of types of } \\
\text { assessment }\end{array}$ & 5 & $\begin{array}{lll}.82 & .73 & .72 \\
.67 & .65 & \end{array}$ & .88 \\
\hline 3 & $\begin{array}{l}\text { Scoring and } \\
\text { grading practice } \\
\text { Use of }\end{array}$ & 14 & $\begin{array}{lll}.61 & .48 & .82 \\
.67 & .82 & .85 \\
.88 & .87 & .81 \\
.85 & .84 & .88 \\
.86 & .85 & \end{array}$ & .96 \\
\hline 4 & $\begin{array}{l}\text { assessment } \\
\text { information } \\
\text { Assessment }\end{array}$ & 8 & $\begin{array}{lll}.52 & .71 & .71 \\
.77 & .72 & .78 \\
.88 & .90 & \end{array}$ & .92 \\
\hline 5 & ethics & 5 & $\begin{array}{lll}.71 & .86 & .83 \\
.74 & .75 & \\
\end{array}$ & .91 \\
\hline & Total & 50 & & .97 \\
\hline
\end{tabular}

\section{Findings}

\subsection{Demographic factors}

A total of 49 respondents representing all English language teachers in all 13 secondary schools in the district of Marang were involved. There were 6 male teachers (12.2\%) and 43 female teachers $(87.8 \%)$. Based on experience involving in SBA, the highest number of respondents is 17 teachers representing $34.7 \%$ of those with 4 years of experience involving in SBA followed by 16 (32.7\%) with 3 years of experience. 8 respondents $(16.3 \%)$ have 1 and 2 years of experience. For training related to SBA, 32 teachers $(65.3 \%)$ have attended courses related to SBA whereas 17 respondents (34.7\%) have not attended any training related to SBA.

\subsection{Descriptive Statistic Analysis for Study Variables}

The comparison of SBA practice ini this study was based on 5 constucts that are skill of constructing assessment instruments, use of types of assessment, scoring and grading practice, use of assessment information and assessment ethics. The analysis for each variable is interpreted by using mean and standard deviation whereas the analysis of each item is interpreted based on frequency, percentage and mean. The mean score interpretation is low (1.00$2.33)$, average (2.34 - 3.67) and high (3.68 - 5.00). From Table 6, it is found that scoring and grading practice in SBA has the highest mean that is 3.42 with standard deviation of .68 whereas use of types of assessment has the lowest mean that is 3.24 with standard deviation of .62. Overall, the SBA practice among English language teachers in marang is at an average level.

Table 4. Mean and Standard Deviation of SBA practice based on constructs

\begin{tabular}{|l|c|c|}
\hline SBA Practice Constructs & Mean & SD \\
\hline $\begin{array}{l}\text { 1.Skill of constructing assessment } \\
\text { instruments }\end{array}$ & 3.39 & .61 \\
\hline 2.Use of types of assessment & 3.24 & .62 \\
\hline 3.Scoring and grading practice & 3.42 & .68 \\
\hline 4.Use of assessment information & 3.26 & .73 \\
\hline 5.Assessment ethics & 3.39 & .72 \\
\hline
\end{tabular}

\subsection{Skills of Constructing Assessment Instruments}

Table 4 shows the Skill of constructing assessment instrument that is items 1 until 18 where item 12 was found to have the lowest mean that is "constructing items usng HOTS" with a mean of 3.2. 61.2\% teachers practice it sometimes, seldom and neve in assessment. This is confirmed by Tecaher 3 :

\section{No, I did not apply HOTS questions because they don't help my students. Most of my students could not answer this type of questions (ET4, 2015).}

Item 4, 'Choosing test items from the reference books as SBA items' has the highest mean value $(M=3.82)$. From the interview sessions, it is found that teachers do not construct their own assessment items but instead, adopt directly from the reference books. This is acknowledged by English Teacher 1 by saying:

I am not fully confident that's why i rely on the reference books. After all they are mostly produced by teachers who are involved in the making of the school textbooks (ET1, 2015).

English Teacher 2 commented:

Constructing the items ourselves is more effective but due to time constraint I adopt directly from the reference books. (ET2, 2015). 


\subsection{Use of Types of Assessment}

Consequently, for types of assessment construct, the item that has the lowest mean is item 14 that is "Using Item Specification Table (IST) to plan assessment" with the mean of 2.94. This was stated by English Teacher as a below:

I do not use Item Specification Table (IST) because SBA does need IST to be done since it is not a summative test. For Mid Term and Final Year Examinations, the examination questions are prepared by JPN. So, I don't have to set my own examination questions (ET4, 2015).

This statement is supported by English Teacher 5 who commented:

We usually adopted from reference books where the questions were prepared according to bands. Thus, there is no need to prepare IST. (ET5, 2015).

For the practice in presenting assessment result construct, item 45 that is "Presenting the assessment result to the students" is seen to be practiced a lot by the teachers with the mean of 3.69. The item that has the lowest mean is item 46 with the mean of 3.06 that is "Explaining the bands to the students and their parents".

\subsection{Scoring and Grading}

For the practice of scoring and grading construct, teachers are found frequently giving feedback verbally to students with the mean of $3.76(71.5 \%)$. This is confirmed by Teacher 5 who claimed:

Delivering it verbally makes it easier for us to talk face to face with the students. (ET5, 2015)

The item that obtained the lowest mean is item 36 that is "Considering giving additional credit based on attendance in deciding bands/grades" with the mean of 3.08 where $63.3 \%$ teachers seldom, once in a while and never practice it. This is admitted by Teacher 2:

Transparency is important. We have to decide the students' bands according to their achievement and not how the principal wants it. I like to see how far the students have performed. I am very stern with my students but it only means $i$ am concern of their future. Obviously we want the students to achieve the bands as expected by the principal but for that to happen, the students have to put in their own effort. (ET2, 2015).

\subsection{Use of Assessment Information}

For the use of assessment information construct, it was found that teachers always use the information to evaluate the increase based on the class that they teach with the mean of 3.57 (63.2\%) whereas item 39 that is "Conducting item analysis for the purpose of summative test (difficulty and decimation index)" which showed the lowest mean that is 2.98 where $67.4 \%$ teachers who sometimes, once in a while and never practice it.

\subsection{Assessment Ethics}

The last construct which is the practice of assessment ethics, majority of the teachers understand and practice the correct assessment ethics with the overall mean of 3.39. Based on the interview, English Teacher 3 and 4 stated:

Naturally, we would like to see our students achieve a high band but to me it is meaningless if we know they actually have not reached that level. It doesn't matter if their band is low. I will not adjust their band to make it look good. (ET 3, 2015).

Usually what I tested will be based on what they have learnt in class. There is no issue of teaching for the purpose of examination. Furthermore, we have to tell the students what they will be tested on so that they can prepare. I am certain, when we set PBS, we have to inform the students what we are going to assess. (ET 4, 2015).

\section{Discussion}

\subsection{Teachers' Practice of SBA}

SBA through classroom assessment has great impact on students' learning. Therefore, classroom assessment should be planned carefully based on students' learning aims, feasibility, validity and reliability of an assessment. Malaysian Examination Syndicate $(L P M)$ has outlined four characteristics of effective SBA (classroom assessment) which is holistic; display the real picture of students' mastery of skills and development in learning, conducted 
continuously and simultaneously with teaching and learning in the classroom, flexibility and variations in assessments according to students' suitability and readiness and is constructed based on the specific performance.

Overall, after four years of its implementation, teachers' practice of SBA is still at the average level. In this study, teachers are found to lack in the practice of effective classroom assessment [11]. Although the assessment was conducted in line with the teaching and learning objectives and the Student Learning Development Guideline (SLDG), teachers are found to not use the Test Spesification Table because they rely too much on reference books and questions set by questions developers in Terengganu State Education Department. TST is an important tool in the construction of classroom assessment because it ensures validity of a measurement tool which also found that teachers do not use TST when palnning and determining the number of items according to learning contents or level of difficulty [9]. Besides, teachers in this study are worried if the assessment tools they developed do not meet the standard quality that when teachers prepare or develop their own assessment tools, the level of difficulty varies and the use of language is sometimes inaccurate [10].

An effective classroom assessment is also influenced by the use of types of assessment. Teachers in this study were found to employ various types of assessment suitable to the English language subject such as essay, open ended response as the type of assessment that they commonly use although they know that SBA in the English language consists of three components namely speaking, writing and reading. The selection of the two methods was actually influenced by the Form 3 Assessment format. The finding is similar with the finding [29], [14] which found that teachers use various methods in conducting assessment.

Teachers are also found to use alternative assessment and observation method at an average level. Teachers lack knowledge and skills in administering assessment, especially alternative assessment, because they lack trainings [9]. Therefore, to ensure SBA implementation achieve its original goal that is to monitor development and help in increasing students' potential, teachers should use various strategies to monitor students' development and achievements in all language skills and functions as specified in the Secondary Schools English Language Syllabus. Among the assessment designs that are progressing and used widely in education is the alternative assessment such as measurement of students' mastery and achievement that are conducted without giving any grades to students like the usual examinations.
It can also display holistic picture of students' ability and improvisation needed. In line with the SBA implementation, among the alternative assessment that can be applied by teachers is written portfolio, group or individual presentation and authentic assessment such as debates and forums. In giving the scores and bands to the students, study findings show that teachers apply various methods of scoring through group work, individual tasks and hands-on activities.

Teachers deliver assessment feedbacks direct to the students because secondary students are maturated enough in taking necessary actions [9]. Teachers in this study are also found to understand and practice good ethics when conducting assessment. Scoring and grading are also done transparently without any biasness or labeling of students, which is in contrast with finding $[5,19]$ that teachers sometimes help students and also change students' grades.

Classroom assessment that is well administered and managed is able to help students in monitoring and evaluating their own learning, guide teaching and learning sessions and also foster cooperation and student-teacher relationship. Communication between teacher and students can be increased when teachers often discuss students' learning development such as their strengths and weaknesses. In this study, the researchers found that classroom assessment conducted by teachers are limited and done just to fulfill the SBA requirement that is determining students' bands and not to identify students' learning development or planning teaching. When teachers administer meaningful assessment for teaching sake and not just determining bands, teachers will help students to monitor their own learning development and at the same time open new perspectives on their own potentials towards becoming fluent in the English language. This is vital as students in Malaysia usually see the English language subject as a killer subject.

\subsection{Implications of the study}

To ensure the smoothness and effectiveness of SBA implementation, teachers should be armed with sufficient skills not only in constructing assessment tools, administering assessments, giving grades, using and delivering assessment results, but also the right ethics in assessing students. The implications of this study are directed to the three organizations namely MOE, JPN, PPD, teaching institutions, curriculum leaders in schools and teachers.

First, the curriculum content for trainee teachers in teaching institutes should be reviewed and improved by emphasizing more on classroom assessment so that teachers to be will have sufficient knowledge and can 
administer effective classroom assessments. Therefore teaching institutes should put importance in this issue in their curriculum.

Secondly, MOE, District and State Education Departments; and schools should ensure that continuous trainings related to SBA be given to teachers so that they have sufficient skills in conducting SBA and thus make it a successful implementation. Trainings related to SBA can be conducted periodically and continuously so that teachers are always exposed and be reminded of the latest assessment practice in education. Besides that, trainings can be diversified based on focused contents such as constructing instruments course, use of assessment information or results; or ethics in the same professional development for all teachers will not be effective and will not bring change to them. The researchers also agree that courses or trainings be given directly by the officers or personnels from the Malaysian Examination Syndicate and MOE and not in top-down stages. This can help in curbing misinterpretation of information or diluted contents which have been happening until now.

At the school level, principals as curriculum leaders supported by senior assistants and senior subject coordinators should draft continuous professional development plan by giving emphasis on courses on assessments to all teachers since classroom assessments involve students in all phases. Schools can also practice professional learning community (PLC) so that teachers can give each other support, expert help and also ideas based on their subject expertise. A one size fits all type of professional development practice should be discarded because good trainings should be individualized and can give significant impact on teachers' assessment practice. Among PLC activities which can be inculcated are peer coaching and teacher sharing session. Supervision based on assessment can also be done by reviewing the reference books used by teachers. Senior subject assistants, subject coordinators and teachers can discuss on the selection of reference books for teachers or students to ensure that they are in concord with students' learning and assessment.

\section{Conclusion}

To conclude, teachers should take the initiatives to increase their knowledge and skills, especially those that are related to classroom assessment. Discussion in professional learning community can also be done so that teachers can exchange information and experiences among themselves and this can indirectly increase their SBA practice. The researchers believe that if concerned parties consider the suggestions mentioned above, SBA practice among teachers can be enhanced and this will give impact on the implementation of SBA as a whole. Good and effective SBA practice will result in the achievement of MOE's aims in producing holistic human capital who are balanced and armed with important skills which are needed in the challenging and dynamic $21^{\text {st }}$ century.

\section{References}

[1]A. Ornstein, and F. Hunkins. Curriculum: Foundations, principles, and issues. Boston, MA: Allyn \&

Bacon. 2009.

[2]A. Brown, and T. D. Green. The essentials of instructional design: Connectionfundamental principles with process and practice. Saddle River, NJ: Pearson Prentice Hall. 2006.

[3]K. S. N. Gopala, Roszainora Setia., Nor Zaitolakma Abdul Samad., Raja Nurul Huda binti Raja Zahri., Azyanee Luqman., V. Thenmolli, and Haslina Che Ngah. Teachers' knowledge and issues in the implementation of schoolbased assessment: A case of schools in Terengganu. Asian Social Science, 10(3), 2014, 186-194.

[4]C. Y. Fook, and G. K. Sidhu. School-based assessment among ESL teachers in Malaysian secondary schools. Malaysian Education Deans' Council Journal, 9, 2011, 7587.

[5]Minstry of Education, Malaysia (2012, November 27). Pentaksiran berasaskan sekolah [Entri daripada blog]. Diakses dari http://buletinkpm.blogspot.com/2012/11/ pentaksiran-berasaskan-sekolah-pbs.html

[6]Salmiah Jaba. Pentaksiran berasaskan sekolah (PBS). 2013.[Entri daripada blog]. Diakses dari, http://salmiahjaba. com/pentaksiran-berasaskan-sekolahpbs/

[7] Rohaya Talib, Mohd Zaki Kamsah, Hamimah Abu Naim, and Adibah Abdul Latif. From principle to practice: Assessment for learning in Malaysian school-based assessment classroom. International Journal of Social Sciences and Education, 4(4), 2014, 850-857.

[8]L. Y. Chun. Practice and challenges of school-based formative assessment. Conference of International Association for Educational Assessment: Assessment in an Era of Rapid Change: Innovations and Best Practices, Singapore.2006. Diakses dari, http://repository.ied.edu.hk/ dspace/handle/2260.2/3148

[9]S. L. Suah, and S. L. Ong. Investigating assessment practices of in-service teachers. International Online Journal of Education Sciences, 4(1), 2012, 91-106.

[10]Ruzlan Md-Ali, V. Arsaythamby, and N. K. Harihahan. Implementation of school-based assesment: The experienced teachers' thoughts. Australian Journal of Basic and Applied Sciences, 9(18), 2015. 72-78. 
[11] G. K. S. Nair, Roszainora Setia, Nor Zaitolakma Abdul Samad, Raja Nurul Huda Raja Zahri, Azyanee Luqman, T. Vadeveloo., and Haslina Che Ngah. Teachers' knowledge and issues in the implementation of schoolbased assessment: A case of schools in Terengganu. Asian Social Science, 10(3), 2014, 186-194.

[12]R. M. Thomas. High-stakes testing: Coping with collateral damage. Mahwah, NJ: Lawrence Erlbaum Associates. 2005.

[13]W. A. Firestone, L. A. Monfils, and R. Y. Schorr. The ambiguity of teaching to the test: Standards, assessment, and educational reform. Mahwah, NJ: Lawrence Erlbaum Associates. 2004.

[14]T. R. Guskey. How classroom assessments can improve learning. Educational Leadership, 60(5), 2003, 7-11.

[15]P. E. Barton. Staying on course in education reform. Princeton, NJ: Statistics \& Research Division, Policy Information. Center, Educational Testing Service. 2002.

[16] T. Eckhout, S. Davis, K. Mickelson, and A. Goodburn. A Method For Providing Assessment Training To InService And Pre-Service Teachers. Kertas dibentangkan di mesyuarat tahunan Southwestern Educational Research Association, New Orleans, LA. 2005.

[17]Khodori Ahmad. Peranan pentaksiran dalam pembentukan masyarakat yang berfikiran dan belajar. International Conference on Teaching and Learning, 2(1), 2000, 468- 475 .

[18] A. M. Alsarimi. Classroom Assessment and Grading Practices In The Sultanate of Oman. Disertasi, University of Pittsburgh, Pennsylvania. 2000.

[19]S. K. Green, R. L. Johnson, D. Kim, and N. S. Pope. Ethics in classroom assessment practices: Issues and attitudes. Teaching and Teacher Education, 23, 2007, 9991011.

[20]Z. Zhang, and J. A. Classroom practices and teachers' self-perceived assessment skills. Applied Measurement in Education, 16(4), 2003, 323-342.

[21]J. C. Nunnally, and I. H. Bernstein. Psychometric Theory ( $3^{\text {rd }}$ ed.). New York: McGraw-Hill. Osburn, H. G. (2000). 